\title{
Chikungunya fever and mental illness: a poorly understood relationship needing additional study
}

\author{
Luís Arthur Brasil Gadelha Farias ${ }^{1}$ \\ https://orcid.org/0000-0002-8978-9903
}

RoBERTO DA JUSTA PIRES NETO ${ }^{1}$

EugÊNIO de Moura CAMPoS²

https://orcid.org/0000-0002-9104-7888

${ }^{1}$ Community Health Department, Federal University of Ceará, Fortaleza, CE, Brazil.

2 Psychiatry Department, Walter Cantídio University Hospital, Fortaleza, CE, Brazil.

Received: 1/29/2019 - Accepted: 2/15/2019

DOl: 10.1590/0101-60830000000206

\section{Dear Editor,}

Chikungunya fever is an acute disease caused by an alphavirus from the Togaviridae family and transmitted by Aedes species mosquitoes, mainly Aedes aegypti. It is recognized as an acute disease characterized by fever, arthralgia, arthritis, and rash, and multiple complications during the chronic phase have been described ${ }^{1}$. These complications may manifest in a variety of organs and systems, including the skin, eyes, and neurological, genitourinary, and cardiac systems $s^{2,3}$. The complete range of chikungunya-induced manifestations is not completely known.

Among psychiatric disorders, an increase in mood disorders, such as depression, has been experienced by some patients during the chronic phase of chikungunya ${ }^{4}$. It is believed that inflammatory biomarkers affecting the central nervous system may be involved in this process. An increase in the levels of interleukin-6 (IL-6) and other cytokines during the acute phase of chikungunya can be related to depression. The fact that IL-6 level remains elevated during the chronic phase is associated with chronic pain, leading to behaviors that may be responsible for the increased risk of mood disorders 5 . The potential of chikungunya fever to cause psychiatric disorders warrants investigation of an organic etiology in cases of mental illness.

Studies have shown that chikungunya virus infection exacerbates prior comorbidities, and conditions such as chronic kidney and autoimmune disease may be exacerbated during the acute phase $\mathrm{e}^{6,7}$. However, no large-scale studies have investigated the relationship between the presence of previous psychiatric conditions and their exacerbation by chikungunya virus infection. Some case reports have suggested that decompensation of prior psychiatric disorders such as bipolar disorder8 occurs, but this relationship remains poorly understood.

Currently, the best evidence is from a 34-patient Indian study by Bhatia et al. 4 , in which patients manifested a myriad of mental illnesses such as anxiety, depression, sleep disorder, panic disorder, somatoform disorder, and neurasthenia. Studies regarding other arboviruses such Zika virus and Dengue virus are scarce, although they do not represent diseases with a chronic component as with chikungunya9.

Chikungunya fever has been a public health problem in Latin America since the first registered cases in 2013, followed by a 2016-2017 outbreak with more than 200,000 confirmed cases in Brazil ${ }^{10}$. Since then, cases have been reported annually in the Latin American region, including Brazil. In Brazil, the virus still remains in circulation, which creates an opportunity for new research and understanding of the disease, as well as its relationship with psychiatric disorders. A possible study design would involve retrospective studies to analyze patients' medical records for the acute

phase and follow-up of symptomatic patients with chronic disease, while seeking to understand the mental health sequelae.

The need for new research is urgent. To our knowledge, little information has been published on the relationship between chikungunya disease and mental illness in the last 5 years, and chikungunya-related mental illness disorders need to be understood. More studies are necessary to understand the pathophysiological mechanisms, risk factors, epidemiologic characteristics, clinical aspects during chikungunya phases, correct management, and treatment.

\section{Financial support}

None.

\section{References}

1. González-Sánchez JA, Ramírez-Arroyo GF. Chikungunya virus: History, geographic distribution, clinical picture, and treatment. P R Health Sci J. 2018;37(4):187-94

2. Bonifay T, Prince C, Neyra C, Demar M, Rousset D, Kallel H, et al. Atypical and severe manifestations of chikungunya virus infection in French Guiana: A hospital-based study. PLoS One. 2018;13(12):e0207406.

3. Farias LABG, Ferragut JM, Pires Neto RJ. Encephalitis and transverse myelitis in dengue and chikungunya coinfection. Rev Soc Bras Med Trop. 2018;51(3):403.

4. Bhatia MS, Gautam P, Jhanjee A. Psychiatric morbidity in patients with chikungunya fever: first report from India. J Clin Diagn Res. 2015;9(10):V01-V03.

5. Sepulveda-Delgado J, Vera-Lastra OL, Trujillo-Murillo K, CansecoÁvila LM, Sánchez-González RA, Gómez-Cruz O, et al. Inflammatory biomarkers, disease activity index, and self-reported disability may be predictors of chronic arthritis after chikungunya infection: brief report. Clin Rheumatol. 2017;36(3):695-99.

6. Tanay A. Chikungunya virus and autoimmunity. Curr Opin Rheumatol. 2017;29(4):389-93

7. Silva Junior GBD, Pinto JR, Mota RMS, Pires Neto RDJ, Daher EF. Impact of Chronic Kidney Disease on Chikungunya Virus Infection Clinical Manifestations and Outcome: Highlights during an Outbreak in Northeastern Brazil. Am J Trop Med Hyg. 2018;99(5):1327-30.

8. Figueiredo T, Dias da Costa M, Segenreich, D. Manic episode after a chikungunya virus infection in a bipolar patient previously stabilized with valproic acid. J Clin Psychopharmacol. 2018;38(4):1-2.

9. Tucci V, Moukaddam N, Meadows J, Shah S, Galwankar SC, Kapur GB The forgotten plague: Psychiatric manifestations of Ebola, Zika, and emerging infectious diseases. J Glob Infect Dis. 2017;9(4):151-6.

10. Yactayo S, Staples JE, Millot V, Cibrelus L, Ramon-Pardo P. Epidemiology of chikungunya in the Americas. J Infec Dis. 2016;214(Suppl 5):S441-5. 